\title{
The Research and Practice of Electrical Engineering and Its Automation Professional Course System for the View of Macroengineering
}

\author{
Xin Yao ${ }^{1,}$, Zailin $\mathrm{Yao}^{2, \text { a }}$ \\ ${ }^{1}$ Electrical and Information Engineering of Beihua University, in Jilin City, Jilin Province. New Hill \\ Street, Longtan District, JilinCity, JilinProvince \\ 2 Shangzhi Electric Power Administration, Shangzhi City, Heilongjiang Province \\ ayaoxin19800518@163.coml
}

Keywords: Macroengineering; Engineering and its automation; Course system

\begin{abstract}
With the progress of The Times, thought the increasing numbers of colleges and universities attach great importance to the cultivation of talents, the essential issue of many colleges and universities is how to orientedly cultivate practical personnel according to the social requisition. This is also the primary need to foster talents. Electrical engineering and automation of colleges and universities mainly locate in cultivation of senior engineering and technical personnel, and provide related services for the regional economic construction. In the process of classroom education, the major mission is to develop the students' learning ability, observation ability, the ability of analyzing and resolving problems. Combined with the view of engineering education theory, modern engineering talents cultivation standards and the environment in colleges and universities, it is vital to optimize the electrical engineering and automation system in colleges and universities, to advocate the students according to their aptitude, to construct innovative practice teaching.
\end{abstract}

\section{Macroengineering education thought}

Put forward by the Americans, the view of macroengineering is mainly used to summarize the experience of engineering education. It follows the rules of the development of the project itself, and pays a close attention to the actual needs of society. Macroengineering is not just the great engineering scale, but also the related theory of knowledge engineering system, which refers to all aspects of the discipline, not just limited to the engineering science itself . Along with the progress of the era, the requirement for engineering personnel also increased significantly. Meanwhile, it also requires that the institutions of higher provide comprehensive education for engineering staff, in order to improve their ability in the aspect of theory and practice. Only in this way can cultivate talents who possess the ability to cope with all kinds of problems in the real life, high comprehensive quality and gracious life values.

\section{Build up electrical engineering and its automation professional talent training curriculum system under the view of macroengineering}

To adapt to the development of The Times, colleges and universities in our country mainly bring up compound application talents. Only in this way can our homeland deal with challenges from engineering and social aspects. Therefore, it is necessary to perfect the relevant institutional system, and to throughoutly reform the system and methods of class teaching. Curriculum system, the basis of the view of macroengineering, can provide students with comprehensive knowledge of theory, so they can effectively solve the troubles and difficulties in real life. The design of curriculum system must take account of professional theory and practice system, trying to fundamentally change the traditional teaching system, and can constantly improve the relevant teaching system, and update the course content according to the requirements of The Times. Thus, only when realizing the combination of theory and practice, can our society train useful engineering application talents. 
(1) Nowadays, the lack of the cultivation system of engineering and its automation talents mainly manifests in fellows: (1) No breakthrough in the original mode of thinking; (2) Overweighting the theory of education overweight and lacking the requirement of practical ability; (3) Lack of the related knowledge of theory and the link with corporation; (4) The teaching way and method not keeping up with the pace of The Times development, etc.

(2) It is important to enhance mutual penetration and mutual fusion of electrical engineering and its automation and other professional. In the improving progress of science and technology, major study field of electrical engineering and its automation has had the earth-shaking change. The contact of electrical engineering, computer technology, communication technology, power electronics technology and automation technology is gradually enhanced. Through mutual integration of various disciplines, enhancing the associated part and compressing the remote part not only keep their own independence, and at the same time, maintain in the bridging between a system.

(3) Updating the electrical engineering and its automation major course content should adapt to the modern development. On the one hand, the development of the engineering technology not merely prompts the unprecedented development of electrical engineering and its automation, but make the electrical engineering and its automation more and more perfect as well. On the other hand, electronic technology and computer technology plays a increasing important role in electrical engineering and its automation professional. Along with the progress of The Times, the rapid rise of the new technology and new information technology, combined with the electrical engineering and other disciplines, make the range of electrical engineering category more wider. only to adapt the development of science and technology and to follow the footsteps of the era, can we meet the needs of modernization.

\section{Building electrical engineering and its automation major innovative practice teaching system}

While previous practice teaching system has improved for several years, it can't satisfy the actual needs of the electrical engineering. Therefore, the electrical engineering and its automation major students' ability is far to meet the social needs. Apparently, students are incomplete to tackle the engineering mission right now, after entering the enterprises and institutions.

The view of macroengineering requires relevant professional talent training to refer to outstanding engineers training cases. Improving the students' engineering practical ability is our urgent problems at present. A long-time study shows that practice teaching played a considerable role in the whole teaching process. That comprehensively train the students in real engineering environment is very effective to improve their personal ability

We divide practical teaching into four parts: The first part, Mainly to raise student's beginning ability, course experiment being open, more students through their existing experience to explore topics, rather than passive learning theoretical knowledge.

The second part, mainly to practice basic engineering, in view of engineering thought and concept to education of students, making them have the basic ability to work through the practice of professional. The third part, mainly to improve the students' ability to solve the analysis of complex engineering, to cultivate students' comprehensive consideration question, thought forms in the tail from wagging the dog. The fourth part, to pay attention to improving the students' ability to solve problems independently, to discard the traditional education idea and to let students study, grope independently and give guidance to them through real life engineering problems.

\section{Form engineering of electrical engineering and its automation professional teacher training mechanism under the view of macroengineering}

The cultivation of the talents is closely related to teachers' teaching, so a strong teaching staff is the precondition of talent cultivation. Nowadays, many universities in China formed a certain system for 
nurturing teachers. And the school plans to hire related personnel with good engineering quality and engineering practice ability. School also cooperate with the relevant enterprises, so the technical personnel of enterprises can not only introduce the project into school, to build a realistic engineering training environment in which teachers and classmates have a chance to understand the engineering environment, but also hold students through on-the-spot operation. School should train teachers and set up the teacher training institutions to let the teacher first field operation, improving the related ability of teacher to cultivate a group of engineering education talents with engineering practice ability, which is the precondition of cultivating talents.

\section{Conclusion}

To cultivate interdisciplinary talents with innovation, practice, the practice teaching link of classroom teaching is particularly important. Electrical engineering and its automation practice teaching in colleges and universities has gradually formed the scale. The practice teaching has also made significant achievements. Institutions and enterprises also give a high evaluation on the improvement of students' theoretical knowledge and practical ability. In order to adapt to the development trend of electrical engineering and its automation specialty and discipline, we must closely combine with the education teaching rule, and constantly enrich the practice teaching system, providing the excellent talents of the relevant aspects for the society, to effectively serve economy and society .

\section{Acknowledgements}

The work is funded by the Jilin provincial electrical engineering and automation brand professional construction fund

\section{References}

[1] Li Ruen, Guan Zhiqiang, Zou Gangming. Macroengineering research sammary [J]. Southern Weekly ,2011, (5):42-45.

[2] Niu Xianchun, Zho Jianming, Zhong Huawen. Under the guidance of the view of macroengineering teaching reform and practice of environmental monitoring [J]. Guangzhou chemicals ,2010, (4):245-246.

[3] Chen Xiaoying, Ren Guochen, Lu Baochun. Reform and practice of talent training mode of electrical engineering and Automation Specialty[J]. Laboratory Sciencen ,2015, (6):85-87.

[4] Lu Huifen, MA Hao, Yang Minhong. The construction of exploratory experiment teaching team of electrical specialty course[J]. Laboratory research and exploration,2015, (10):56-59.

[5] Xiong Zhonggang,Reform of teaching methods and means of "electrical engineering foundation" course[J] .Science and technology information ,2015,(24):77-79. 